
\title{
$\begin{array}{ll}\text { Research Square } & \begin{array}{l}\text { Preprints are preliminary reports that have not undergone peer review. } \\ \text { They should not be considered conclusive, used to inform clinical practice, } \\ \text { or referenced by the media as validated information. }\end{array}\end{array}$
}

\section{Applicability and Improvement of Different Evapotranspiration Methods of Reference Crops in Jiangxi Province}

\author{
Xianghui Lu ( $\sim$ xianghuilu@nit.edu.cn ) \\ Nanchang Institute of Technology \\ Haina Zhang \\ Nanchang Institute of Technology \\ Yixiu Han \\ Nanchang Institute of Technology \\ Hua Bai \\ Nanchang Institute of Technology \\ Erhui Li \\ Nanchang Institute of Technology
}

\section{Research Article}

Keywords: Reference crop evapotranspiration, Jiangxi province, Turc method, Pristley-Taylor method

Posted Date: September 30th, 2021

DOI: https://doi.org/10.21203/rs.3.rs-262268/v1

License: (c) (i) This work is licensed under a Creative Commons Attribution 4.0 International License. Read Full License

Version of Record: A version of this preprint was published at Theoretical and Applied Climatology on October 16th, 2021. See the published version at https://doi.org/10.1007/s00704-021-03806-7. 


\section{Abstract}

To achieve accurate evaluation of evapotranspiration of reference crops (ET0) in Jiangxi, China in the absence of systematic climatological data, with reference to the FAO-56 Penman-Monteith (P-M) equation, the Pristley-Taylor (P-T) method, the Makkink method, the Hargreaves-Samani (H-S) method, the Irmak-Allen (I-A) method, the Penman1948 (48PM) method, the Penman-Van Bavel (PVB) method, the Baier-Robertson (B-R) method, the improved Baier-Robertson (M-B-R) method, the Schendel (Sch) method, the Turc method, the Jensen-Haise (J-H) method, and the Brutsaert-Stricker (B-S) method were used to evaluate the daily climatological data collected by 26 weather stations in Jiangxi, China and 17 weather stations in adjacent provinces. The results were compared with each other and parameter rate determination was conducted. The results indicated that the Turc method exhibited optimized applicability before parameter rate determination and the average root mean square error (RMSE) and the average normalized root mean square error (NRMSE) by this method were $0.39 \mathrm{~mm} / \mathrm{d}$ and $0.157 \mathrm{~mm}$, respectively. However, parameter rate determination led to negligible improvement in accuracy for this method. The Turc method could be directly applied in Jiangxi (except Nanchang). For special distribution of error after parameter rate determination, all methods exhibited significant errors in Northern Jiangxi. Herein, the 48PM method and the B-S method showed good applicability after parameter rate determination and RMSE and NRMSE of data by these methods ranged in $0.06 \sim 0.34 \mathrm{~mm} / \mathrm{d}$ and $0.08 \sim 0.27,8 \sim 27 \%$ respectively, and their d-indices were close to 1 . The annual over-estimations in weather stations in Jiangxi were below $30 \mathrm{~mm}$. In the absence of data about relative humidity and wind speed, the P-T method was an appropriate simplified method for Jiangxi. In this case, a was slightly lower than the default value (1.05 1.18), RMSE was within $0.21 \sim 0.66 \mathrm{~mm} / \mathrm{d}$, and NRMSE was within $0.08 \sim 0.308 \sim 30 \%$. Accuracy of RMSE, d-index, and NRMSE of data by the P-T method, the I-A method, and the PVB method were consistent with all stations, while that by the Mak method was slightly lower, which could be attributed to severe overestimation in July and August. RMSE of the H-S method, the B-R method, the M-B-R method, the J-H method, and the Sch method were above $0.75 \mathrm{~mm} / \mathrm{d}$ and these methods were not suitable for accurate evaluation of ETO in Jiangxi, China. The annual ET0 was calculated by various methods (except the 48PM method and the B-S method) exhibited significant variation around 2003. This may be attributed to significant changes in certain meteorological factors over recent years.

\section{Highlights}

- Evapotranspiration of reference crops (ET0) in Jiangxi were evaluated by 26 weather stations in Jiangxi, China and 17 weather stations in adjacent provinces.

- The Turc method exhibited optimized applicability before parameter rate determination, and could be directly applied in Jiangxi (except Nanchang).

- In the absence of data about relative humidity and wind speed, the P-T method was an appropriate simplified method for Jiangxi.

- RMSE of the H-S method, the B-R method, the M-B-R method, the J-H method, and the Sch method were above $0.75 \mathrm{~mm} / \mathrm{d}$ and these methods were not suitable for accurate evaluation of ETO in Jiangxi, China.

\section{Introduction}

As basic data for determination of water demands of crops, the reference crop evapotranspiration is a key factor affecting the estimation accuracy of water demands of crops (Liu, Li, \& Wang, 2006), as well as one of the key factors in irrigation system planning and hydrological model establishment (Allen, Pereira, Raes, \& Smith, 1998; Wang, Peng, Yang, Shao, \& Xing, 2011). Owing to its wide applicability globally, the FAO Penman-Monteith (P-M) method was set by united nations food agriculture organization (FAO) as the standard method for evaluation of $\mathrm{ET}_{0}$ (Allen, Pereira, Raes, \& Smith, 1998). However, the P-M method has a high requirement on the integrity of climatological data. Therefore, various simplified methods, including the temperature-based Hargreaves-Samani (H-S) method (Hargreaves, \& Allen, 2003), the radiation-based IrMak method (Irmak, Irmak, Allen, \& Jones), the Makkink method (Makkink, 1957), and the Pristley-Taylor (P-T) method (Du et al., 2013), have been widely used. Additionally, the FAO 24 Penman radiation method (Zhang, Duan, Gao, Shen, \& Cai, 2015) and the Penman-Van Bavel (PVB) method (Yuan, Yang, Chen, \& Wu, 2014) have also attracted great attentions. Nevertheless, applications of these methods are limited by local climate and geographic conditions and many models cannot be directly applied. Many researchers have examined the applicability of different evapotranspiration models in different locations. For example, Djaman et al. (2015) assessed 16 ET0 models in the Senegal River Valley, Muniandy et al. (2016) tested 26 ET0 models in Kluang, Malaysia, indicating that thetemperature based models tend to overestimate ET values. The Penman and Rohwer models perform better than the Penman Monteith model. Akhavan et al. (2018) assessed and ranked different evapotranspiration models in daily corn evapotranspiration, the Hargreaves-M3 model (RMSE $=1.89 \mathrm{~mm} /$ day) in the temperature-based models, the Caprio (1974) model (RMSE = $1.99 \mathrm{~mm} /$ day) in the radiation-based models, and the Albrecht (1950) model (RMSE $=4.33 \mathrm{~mm} /$ day) in the mass transfer-based models were ranked first place. Paredes et al. (2018) assessed the PMT method (ETo PMT) and the HS equation (ETo HS), and the result showed 
that the PMT approach is more accurate than HS in the humid environments of Azores islands. Li et. al. (2016) compared the applicability of six simplified methods, including the Penman (48PM) method, the PVB method, the H-S method, the P-T method, the I-A method, and the Mak method, in different climatic regions of Sichuan, China, suggesting that the H-S method should be used in Eastern Sichuan and the P-T method should be used in other regions. Zhang et. al. (2015) evaluated the applicability of eight methods (including the Irmak method, the H-S method, the P-M method) in Xinxiang, Henan and recommended the corrected Irmak method for this region. Wu et. al. ( 2016) evaluated the applicability of various methods (including the H-S method) in Northwestern China and proposed alternative methods in the absence of climatological data. Nonetheless, reference evapotranspiration estimation is valuable when it is used in calculating actual evapotranspiration.

Jiangxi Province located in Southeastern China, is in a central subtropical humid monsoon climatic region and is famous as one of the key rice producing areas in China owing to its rich hydrothermal resources. However, water resources and thermal resources may appear in different periods, resulting in droughts and floods. Indeed, summer droughts and/or floods are frequently observed, especially in July and August, resulting in severe threats to high and stable yields of rice. Additionally, Jiangxi shows varying geographical conditions and climates, but few weather stations (<30) can provide long time meteorological data. Therefore, appropriate calculation methods for evapotranspiration of reference crops should be determined for the design of irrigation and drainage system. The farmland in this region is mostly managed by farmers, who usually lack higher education and have difficulty mastering the latest technology. Therefore, it is meaningful to establish a simpler ETO model than any advanced methods. However, there is a lack of systematic comparison and feasibility evaluation of simple ETO models for this region. For investigating the applicability of different calculation methods in Jiangxi and parameter localization, and eventually selection of optimized method, $E T_{0}$ has been simulated in daily scale by the 48PM method, the $\mathrm{H}-\mathrm{S}$ method, the P-T method, the I-A method, the Mak method, the PVB method, the Baier-Robertson (B-R) method, the improved BaierRobertson(M-B-R) method, the Schendel (Sch) method, the Turc method, the Jensen-Haise (J-H) method, and the Brutsaert-Stricker (B-S) method. The applicability of these methods was evaluated using the FA056 P-M method as the reference and parameters of these methods were predetermined to select appropriate calculation method for evapotranspiration of reference crops in Jiangxi.

\section{Materials And Methods}

\subsection{Background Of Testing Region}

Located at the south of the middle and lower reaches of Yangtse River, Jiangxi $\left(24^{\circ} 29^{\prime} \mathrm{N}-30^{\circ} 04^{\prime} \mathrm{N}, 113^{\circ} 34^{\prime} \mathrm{E}-118^{\circ} 28^{\prime} \mathrm{E}\right) \mathrm{consists}^{\circ}$ of Boyang Lake Plain (the north part), Jiangnan Hill (the south part), and mountains (the east and west part), as shown in Fig. 1. As a typical central subtropical humid monsoon climatic region, Jiangxi has average annual temperature of $16.3-19.5^{\circ} \mathrm{C}$ (increased from north to south) and average annual precipitation of $1600 \mathrm{~mm}$.

\subsection{Data source}

The daily climatological data (including hours of sunshine, average temperature, maximum temperature, minimum temperature, relative humidity, and wind speed at $2 \mathrm{~m}$ ) collected from 26 weather stations in Jiangxi and 17 weather stations in provinces adjacent to Jiangxi (Fig. 1) in this study were obtained from National Meteorological Science data sharing Center of China and the monthly and annual ET0 were calculated based on the daily data. In order to compare the accuracy of different ET0 estimation methods, the quality control of meteorological data was carried out: when one or more of the daily meteorological data was missing, all the data of that day were deleted.

\subsection{Methods}

Twelve ETO estimation methods were used to calculate reference crop evapotranspiration, and compared with ET0 estimation methods in FA056P-M (Table 1). 
Table1 Methods of Reference crop evapotranspiration calculation.

\begin{tabular}{|c|c|c|c|}
\hline $\begin{array}{l}\text { Mod } \\
\text { elID }\end{array}$ & Model name & Model equation & Model parameter default value \\
\hline 0 & $\begin{array}{c}\text { FA056 } \\
\text { Penman-Monteit } \\
\text { h } \\
\text { [FAO56 P-M] }\end{array}$ & $E T_{0}=\frac{0.408 \Delta\left(R_{n}-G\right)+\gamma \frac{900}{T+273} u_{2}\left(e_{x}-e_{\alpha}\right)}{\Delta+\gamma\left(1+0.34 u_{2}\right)}$ & $a=0.13, b=0.57$ (Jiangxi Province) $\mid 177$ \\
\hline 1 & $\begin{array}{l}\text { Penman1948 } \\
{[48 \mathrm{PM}]^{[12]}}\end{array}$ & $E T_{0}=\frac{1}{\lambda} \frac{\Delta}{\Delta+\gamma}\left(R_{x}-G\right)+a \frac{\gamma}{\Delta+\gamma}\left(1+b u_{2}\right)\left(e_{x}-e_{x}\right)$ & $a=6.43, b=0.536$ \\
\hline 2 & $\begin{array}{l}\text { Hargreaves-Sam } \\
\text { ani }(\mathrm{H}-\mathrm{S})^{[\mathrm{la|}}\end{array}$ & $E T_{0}=\frac{a}{\lambda}\left(T_{\max }-T_{\min }\right)^{b}\left(T_{\max n}+c\right) R_{\alpha}$ & $a=0.0023, b=0.5, c=17.8$ \\
\hline 3 & $\begin{array}{l}\text { Pristley-Tayler } \\
\qquad[\mathrm{P}-\mathrm{T}]^{\mid 7]}\end{array}$ & $E T_{0}=\frac{\alpha}{\lambda} \frac{\Delta}{\Delta+\gamma}\left(R_{n}-G\right)$ & $\alpha=1.26$ \\
\hline 4 & $\begin{array}{l}\text { Irmak-Allen }[(1-\mathrm{A}) \\
|\epsilon|\end{array}$ & $E T_{0}=a+b R_{n}+c T_{\max n}$ & $a=0.489, b=0.289, c=0.023$ \\
\hline 5 & Makkink (Mak) & $E T_{0}=\frac{a}{\lambda} \frac{\Delta}{\Delta+\gamma} R_{x}-b$ & $a=0.61, b=-0.12$ \\
\hline 6 & $\begin{array}{l}\text { Penman-Van } \\
\text { Bavel (PVB) }{ }^{120]}\end{array}$ & $E T_{0}=\frac{\left(a T_{\operatorname{man}}^{2}-b T_{\operatorname{man}}+c\right) \frac{R_{n}}{\lambda}+\frac{u_{2}+0.1}{80.8}\left(e_{x}-e_{a}\right)}{\left(a T_{\operatorname{man}}^{2}-b T_{\operatorname{man}}+c\right)+1}$ & $a=0.00309, b=-0.00264516, c=0.9246$ \\
\hline 7 & $\begin{array}{l}\text { Baier-Robertson } \\
\qquad[B-R]^{\mid 120]}\end{array}$ & $E T_{0}=a T_{\max }+b\left(T_{\max }-T_{\max }\right)+c R_{x}+d$ & $a=0.157, b=0.158, c=0.109, d=-5.39$ \\
\hline 8 & $\begin{array}{l}\text { Modified } \\
\text { Baier-Robertson } \\
{[M-B-R)^{\mid 12]}}\end{array}$ & $E T_{0}=a\left(T_{\max }-T_{\max }\right)+b R_{x}+c\left(e_{x}-e_{a}\right)+d T_{\max }+e$ & $\begin{array}{l}G=0.1844, b=0.1135, c=2.811, d=-0.0039, e \\
=-4.04\end{array}$ \\
\hline 9 & Schendel (Sch) $)^{\mid[x]}$ & $E T_{0}=a \frac{T}{R H}$ & $a=16$ \\
\hline 10 & Turc ${ }^{12 \mid}$ & $E T_{0}=a \frac{\left[b \times(c+d \bar{N})^{R_{x}+}\right.}{T_{\operatorname{mana}}+15}$ & $a=0.013, b=23.8 B, c=0.25, d=0.5$ \\
\hline 11 & $\begin{array}{l}\text { Jensen-Haise } \\
\qquad(J-H)^{1150}\end{array}$ & $E T_{0}=a\left(b T_{\operatorname{maxin}}+c\right) \times 0.408 \times\left(d+e \frac{n}{N}\right) R_{x}$ & $G=0.87, b=0.025, c=0.075, d=0.25, e=0.5$ \\
\hline 12 & $\begin{array}{l}\text { Brutsaert-Stricke } \\
r(B-S)^{112 a}\end{array}$ & $\left.E T_{a}=(2 a-1) \frac{\Delta}{\Delta+\gamma}\left(R_{n}-G\right)-\frac{\gamma}{\Delta+\gamma}\left[b\left(1+b u_{2}\right)\right] e_{c}-e_{a}\right)$ & $a=1.28, \quad b=0.26, c=0.86$ \\
\hline
\end{tabular}

Note: $E T_{0}$ refers to the reference crop evapotranspiration $(\mathrm{mm} / \mathrm{d}), R_{n}$ refers to the net radiation $\left(\mathrm{MJ} /\left(\mathrm{m}^{2} \cdot \mathrm{d}\right)\right), R_{s}$ refers to the overall surface radiation $\left(\mathrm{MJ} /\left(\mathrm{m}^{2} \cdot \mathrm{d}\right)\right), G$ refers to the soil heat flux density $\left(\mathrm{MJ} /\left(\mathrm{m}^{2} \cdot \mathrm{d}\right)\right), T$ refers to the average temperature at $2 \mathrm{~m}\left({ }^{\circ} \mathrm{C}\right), u_{2}$ refers to the wind speed at $2 \mathrm{~m}(\mathrm{~m} / \mathrm{s}), e_{\mathrm{s}}$ refers to the saturation vapor pressure $(\mathrm{kPa}), e_{\mathrm{a}}$ refers to the actual vapor pressure $(\mathrm{kPa}), \Delta$ refers to the slope of temperature-vapor pressure curve $\left(\mathrm{kPa} /{ }^{\circ} \mathrm{C}\right), y$ refers to the hydrometer constant $\left(\mathrm{kPa} /{ }^{\circ} \mathrm{C}\right), \lambda$ refers to the latent heat constant of

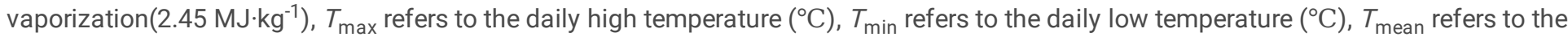
daily average temperature $\left({ }^{\circ} \mathrm{C}\right), \mathrm{RH}$ refers to the relative humidity $(\%)$.

\subsection{Statistical evaluation and data processing}

Four evaluation indices, including the root mean square error $\left(\mathrm{R}_{\mathrm{MSE}}\right)$, consistency coefficient (d-index), normalized root mean square error $\left(\mathrm{N}_{\mathrm{RMSE}}\right)$, and average deviation $\left(\mathrm{M}_{\mathrm{BE}}\right)$, commonly used for evaluation of reference crop evapotranspiration were used and the equations are as follows:

$$
d-\text { index }=1-\frac{\sum_{i=1}^{n}(C-P)^{2}}{\sum_{i=1}^{n}(|C-\mathbb{C}|+|P-\mathbb{E}|)^{2}}
$$




$$
M_{B E}=\frac{1}{n} \sum_{i=1}^{n}\left(C_{i}-P_{i}\right)
$$

$$
R_{M S E}=\sqrt{\frac{1}{n} \sum_{i=1}^{n}\left(C_{i}-P_{i}\right)^{2}}
$$

3

$$
N_{R M S E}=R_{M S E} / \mathbb{E} \times 100 \%
$$

4

where $\mathrm{n}$ refers to the sample size, $\mathrm{C}$ refers to the observed values, $\mathrm{P}$ refers to the simulated values, Crefers to the average observed value.

Parameter redetermination of different reference crop evapotranspiration calculation methods were achieved using the Isqcurvefit function in MATLAB 2014a. To simplify the models, the parameters of all models were redetermined twice. After the first round, the average of parameters collected by different stations was set as the value of this specific if the coefficient of variation (CV) was below 0.1 . If not, the parameters were redetermined again.

\section{Results}

\subsection{Statistical results of different evapotranspiration methods}

Figure 2 compares the daily scale statistical results of the 12 evapotranspiration calculation methods and the P-M method under default conditions. As observed, applicability of these methods varied significantly. The Turc method exhibited best applicability, followed by the P-T method. Indeed, $\mathrm{R}_{\mathrm{MSE}}$ of data by the Turc method and the P-T method were significantly lower than those of other methods, while dindex of data of the two methods were significantly higher than those of other methods. The medians of $\mathrm{N}_{\text {RMSE }}$ of data obtained by the Turc method and the P-T method were 0.16 and 0.20 , respectively. According to MBE, deviations of under-estimation and over-estimation were relatively small for both methods, indicating better performance of the Turc method. Nevertheless, outliers in box plots demonstrated that accuracy of data collected by certain stations by the Turc method was lower than that by the P-T method. The average $\mathrm{R}_{\text {MSE }}$ of data by other 10 methods exceeded $0.75 \mathrm{~mm} / \mathrm{d}$ and these methods were not applicable in Jiangxi. Especially, the 48PM method and the B-S method had identical requirements on the integrity of climatological data as the P-M method, but their accuracies were poor (the accuracy of the 48PM method is slightly higher than that of the B-S method). For the 48PM method, median of $R_{M S E}$ was approximately $2 \mathrm{~mm} / \mathrm{d}$, $\mathrm{d}$ index was below $0.9, \mathrm{~N}_{\text {RMSE }}$ was significantly higher than 0.4 , and MBE was over-estimated by $1.5 \mathrm{~mm} / \mathrm{d}$. For the $B-S$ method, most $R_{M S E}$ were above $6 \mathrm{~mm} / \mathrm{d}$, d-index was below 0.6, $\mathrm{N}_{\mathrm{RMSE}}$ was significantly higher than 0.4, and MBE was over-estimated by $4 \mathrm{~mm} / \mathrm{d}$. In summary, the methods other than the Turc method and the P-T method could not be directly applied in Jiangxi before localized redetermination.

\subsection{Redetermined statistical results of different evapotranspiration calculation methods}

Figure 2 compares the redetermined daily scale statistical results of 12 evapotranspiration calculation methods and the P-M method. As observed, the accuracy of all evapotranspiration calculation methods was significantly improved after redetermination and the amplitudes varied significantly. Herein, the B-S method showed the greatest improvement (minimum RMSE, all medians $<0.1 \mathrm{~mm} / \mathrm{d}, \mathrm{d}$-index $\approx 1$, NRMSE $<10 \%$ ) and optimized applicability after model redetermination (close to that of the P-M method). Additionally, RMSE of data by the 48PM method was low and the NRMSE was below $10 \%$ (except Nanchang, which may be attributed to over-estimation, according to $\mathrm{MBE})$.

The RMSE, d-index, and NRMSE of data by the P-T method, the I-A method, and the PVB method were close to each other. The accuracy of the P-T method, the I-A method, and the PVB method was lower than that of the B-S method and the 48PM method while higher than that of other methods. Herein, under-estimation of the P-T method was $0 \sim 1.4 \mathrm{~mm} / \mathrm{d}$, that of the PVB method was below $0.3 \mathrm{~mm} / \mathrm{d}$, and that of the I-A method was negligible. In terms of the climatological data required, the PVB method has the highest requirement on the integrity of data set: the data of relative humidity and wind speed (not required in the P-T method and the I-A method) were required for calculation of 
actual vapor pressures and canopy resistances. However, the PVB method exhibited no significant advantages in accuracy over the P-T method and the I-A method. Therefore, the PVB method was not applicable in Jiangxi.

The Mak method shared a similar structure with the P-T method. $\mathrm{R}_{\text {MSE }}$ and N $_{\text {RME }}$ of the Mak method was slightly higher than that of the PT method, the I-A method, and the PVB method; d-index of the Mak method was slightly lower than that of the P-T method, the I-A method, and the PVB method, while MBE of the Mak method indicated neither over-estimation nor under-estimation. In summary, the Mak method was slightly inferior to the P-T method in terms of applicability. Considering the fact that the requirements on climatological data by the Mak method and the P-T method were consistent, the P-T method was preferred in this area.

The accuracy of the Turc method and the Mak method were consistent, while parameter redetermination brought negligible improvements on the accuracy of the Turc method. For the Turc method, the defaults of $\mathrm{R}_{\mathrm{MSE}}$ and $\mathrm{N}_{\mathrm{RMSE}}$ were $0.389 \mathrm{~mm} / \mathrm{d}$ and $0.157 \mathrm{~mm}$, respectively, while the redetermined $\mathrm{R}_{\mathrm{MSE}}$ and $\mathrm{N}_{\mathrm{RMSE}}$ were $0.375 \mathrm{~mm} / \mathrm{d}$ and $0.151 \mathrm{~mm}$, respectively. In other words, the Turc method could be directly applied in Jiangxi (except Nanchang, where $\mathrm{R}_{\mathrm{MSE}}=0.972 \mathrm{~mm} / \mathrm{d}$ ) without parameter redetermination. The average $\mathrm{R}_{\mathrm{MSE}}$ of data by the H-S method before and after parameter reetermination were $0.75 \mathrm{~mm} / \mathrm{d}$ and $0.70 \mathrm{~mm} / \mathrm{d}$, respectively, indicating negligible accuracy improvement by parameter redetermination.

The average $R_{M S E}$ of data by the B-R method and the M-B-R method before parameter redetermination were $1.49 \mathrm{~mm} / \mathrm{d}$ and $0.91 \mathrm{~mm} / \mathrm{d}$, respectively, while the rate-determined average $R_{\text {MSE }}$ of data by the B-R method and the M-B-R method were $0.85 \mathrm{~mm} / \mathrm{d}$ and $0.55 \mathrm{~mm} / \mathrm{d}$, respectively. This demonstrated significant accuracy improvement by parameter redetermination for the B-R method and the M-B-R method. Herein, the B-R method required temperature data but its accuracy was lower than that of the H-S method, indicating that the B-R method was not applicable in Jiangxi. In the presence of data about relative humidity, the M-B-R method showed better accuracy compared with the H-S method. However, the M-B-R method required five empirical parameters and this may be a major factor limiting the model application. The accuracy of the Sch method was still relatively low after parameter redetermination: the average RMSE was approximately $0.8 \mathrm{~mm} / \mathrm{d}$, the $\mathrm{d}$-index ranged in $0.85 \sim 0.95$, and the average NRMSE was above 0.3. Hence, the Sch method was not applicable in Jiangxi.

The $\mathrm{J}-\mathrm{H}$ method requires sunshine data and this increases the model complexity. However, $\mathrm{R}_{\mathrm{MSE}}$ of the $\mathrm{J}-\mathrm{H}$ method was increased by 0.3 $\mathrm{mm} / \mathrm{d}$ compared with the I-A model, which required similar data with the $\mathrm{J}-\mathrm{H}$ method, and accuracy improvement over the $\mathrm{H}$-S model, which requires temperature data only, was limited. Therefore, the $\mathrm{J}-\mathrm{H}$ method showed poor applicability and was not applicable in Jiangxi.

\subsection{Redetermined parameters of different evapotranspiration calculation methods}

The parameters were determined based on the results by the P-M method, and the linear regressions of different evapotranspiration calculation methods to the P-M method were established using the least square method. To simplify calculation methods, the secondary regression was applied for some methods. Specifically, if CV is relatively small after primary regression, average of values collected by different stations is defined as the value of this specific parameter and other parameters are using the least square method. Table 2 summarizes redetermined parameters of different evapotranspiration calculation methods. 
Table 2

Calibration parameter value of different reference crop evapotranspiration methods (48PM, H-S, P-T, I-A, Mak, PVB and B-R)

\begin{tabular}{|c|c|c|c|c|c|c|c|c|c|c|c|c|c|c|}
\hline \multirow[t]{2}{*}{ Station name } & \multirow{2}{*}{$\begin{array}{l}\text { 48PM } \\
a\end{array}$} & \multicolumn{3}{|l|}{$\mathrm{H}-\mathrm{S}$} & \multirow{2}{*}{$\begin{array}{l}\text { P-T } \\
a\end{array}$} & \multirow{2}{*}{$\begin{array}{l}\mathrm{I}-\mathrm{A} \\
\mathrm{a}\end{array}$} & \multirow{2}{*}{$\begin{array}{l}\text { Mak } \\
\text { a }\end{array}$} & \multicolumn{3}{|l|}{ PVB } & \multicolumn{4}{|l|}{ B-R } \\
\hline & & a & b & c & & & & a & b & c & a & b & c & d \\
\hline Xiushui & 0.91 & 0.0013 & 0.70 & 15.6 & 1.08 & -0.63 & -0.15 & 113 & -19.1 & -0.36 & 0.09 & 0.07 & 0.04 & 1.82 \\
\hline Yifeng & 81 & 0.0011 & 0.80 & 12.7 & 1.06 & -0.68 & -0.12 & 9 & -20.0 & 0.49 & 0.09 & 0.09 & 0.04 & 2.06 \\
\hline Lianhua & 00 & 0.0015 & 0.72 & 9.1 & 1.08 & -0.63 & -0.16 & 1 & -14.3 & -0.31 & 0.10 & 0.08 & 0.05 & 2.14 \\
\hline Yichun & 1 & 013 & 0.74 & 17.6 & 1.12 & -0.55 & -0.24 & 122 & -28.8 & -0.91 & 0.10 & 0.11 & 0.04 & 1.82 \\
\hline Ji'an & 1.17 & 0.0018 & 0.71 & 8.4 & 1.16 & -0.44 & -0.33 & 667 & 55.7 & 2.35 & 0.12 & 0.08 & 0.03 & 1.83 \\
\hline Jinggangshan & 0.83 & 0.0009 & 0.81 & 28.5 & 1.05 & -0.69 & -0.08 & -81 & -52.0 & -1.60 & 0.06 & 0.12 & 0.05 & 1.78 \\
\hline Suichuan & 1.18 & 0.0017 & 0.67 & 12.4 & 1.17 & -0.45 & -0.33 & 624 & 45.4 & 1.88 & 0.11 & 0.10 & 0.04 & 1.99 \\
\hline Ganzhou & 1.14 & 0.0022 & 0.62 & 7.6 & 1.15 & -0.44 & -0.31 & 550 & 42.9 & 2.22 & 0.12 & 0.07 & 0.04 & 1.94 \\
\hline Lushan & 1.06 & 0.0017 & 0.72 & 24.4 & 1.15 & -0.45 & -0.19 & -379 & -113.7 & -3.43 & 0.12 & 0.14 & 0.00 & 0.60 \\
\hline Wu'an & 1.06 & 0.0012 & 0.73 & 21.8 & 1.12 & -0.53 & -0.24 & 131 & -20.7 & -0.22 & 0.09 & 0.10 & 0.04 & 1.70 \\
\hline Boyang & 1.18 & 0.0018 & 0.73 & 13.2 & 1.18 & -0.35 & -0.37 & 439 & 17.1 & 1.4 & 0.13 & 0.11 & 0.02 & 1.61 \\
\hline Jingdezhen & 1.14 & 0.0014 & 0.72 & 14.5 & 1.15 & -0.47 & -0.28 & 27 & -4 & $0=$ & 0.11 & 0.09 & 0.04 & 1.93 \\
\hline Jing'an & 115 & 0.0009 & 0.92 & 21.4 & 1.15 & -0.46 & -0.29 & -115 & -81.7 & -3.01 & 0.10 & 0.14 & 0.04 & 2.08 \\
\hline Nanchang & 1.19 & 0.0019 & 0.67 & 17.3 & 1.17 & -0.37 & -0.37 & 141 & -38.7 & -0.95 & 0.13 & 0.10 & 0.01 & 1.15 \\
\hline Zhangshu & 1.03 & 0.0018 & 0.68 & 9.9 & 1.12 & -0.54 & -0.24 & 395 & 27.6 & 1.58 & 0.11 & 0.08 & 0.03 & 1.78 \\
\hline Dexing & 1.00 & 0. & 0.75 & 12.2 & 1.09 & -0.60 & -0 & 7 & -29.2 & 0 & 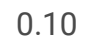 & 8 & 0.04 & 1.95 \\
\hline Guixi & 1.21 & 0.0017 & 0.69 & 13.2 & 1.18 & -0.41 & -0.33 & 527 & 21 & 0. & 0.12 & 0.09 & 0.02 & 1.71 \\
\hline Yushan & 1.14 & 0.0015 & 0.70 & 17.8 & 1.15 & -0.45 & -0.30 & 257 & -11.3 & 0.01 & 0.11 & 0.09 & 0.03 & 1.69 \\
\hline Shangrao & 1.08 & 0.0015 & 0.72 & 14.3 & 1.13 & -0.50 & -0.23 & 261 & -5 & 0.13 & 0.11 & 0.09 & 0.03 & 1.93 \\
\hline Yongf & 1.04 & 0016 & 0.68 & 9.3 & 1 & -0 . & -0.25 & 2 & -1 & 0 & 0 & 0.07 & 0.04 & 1.88 \\
\hline Nancl & 1.14 & 0.0019 & 0.68 & 9.8 & 1.17 & -0.41 & -0.37 & 593 & 37.3 & 1.56 & 0.12 & 0.08 & 0.03 & 1.76 \\
\hline Nanfeng & 1.16 & 0.0020 & 0.65 & 7.6 & 1.16 & -0.45 & -0.33 & 682 & 60.2 & 2.63 & 0.12 & 0.06 & 0.03 & 1.86 \\
\hline Ningdu & 1.11 & 0.0016 & 0.70 & 13.6 & 1.15 & -0.44 & -0.32 & 84 & -43.7 & -1.20 & 0.12 & 0.08 & 0.03 & 1.90 \\
\hline Guang & 1.00 & 0.0016 & 0.70 & 9.0 & 1. & -0.57 & -0.22 & 260 & 1 & 0. & 0.11 & 0.07 & 0.04 & 1.93 \\
\hline Longnan & 1.11 & 0.0016 & 0.63 & 19.4 & 1.09 & -0.55 & -0.25 & -162 & -65.1 & -1.40 & 0.10 & 0.07 & 0.04 & 1.58 \\
\hline Xunwu & 1.07 & 0.0013 & 0.68 & 21.0 & 1.08 & -0.59 & -0.19 & -28 & -33.0 & 0.22 & 0.09 & 0.08 & 0.04 & 1.78 \\
\hline Maximum & 1.21 & 0.0022 & 0.92 & 28.47 & 1.18 & -0.35 & -0.08 & 681.9 & 60.2 & 2.63 & 0.13 & 0.14 & 0.05 & 2.14 \\
\hline Minimum & 0.81 & 0.0009 & 0.62 & 7.59 & 1.05 & -0.69 & -0.37 & -378.6 & -113.7 & -3.43 & 0.06 & 0.06 & 0.00 & 0.60 \\
\hline Average & 1.07 & 0015 & 0.71 & 14.67 & 1.13 & -0.51 & -0.26 & 228.1 & -10.5 & 0.04 & 0.11 & 0.09 & 0.03 & 1.78 \\
\hline
\end{tabular}

The redetermined parameter a of the 48PM method ranged in $0.81 \sim 1.21$ in Jiangxi and was lower than the default value (6.43),

demonstrating that the contribution to the reference crop evapotranspiration by the aerodynamic term would be over-estimated when this method was applied in Jiangxi. Indeed, the result was over-estimated by $1 \sim 2.2 \mathrm{~mm} / \mathrm{d}$. After redetermination, under-estimations of most stations were below $0.05 \mathrm{~mm} / \mathrm{d}$ while few were around $0.18 \mathrm{~mm} / \mathrm{d}$. Future studies may divide Jiangxi into several districts according to the climate and align parameters within the specific district. In this way, applicability of a model may be improved without affecting its accuracy (Table 2). 
The redetermined parameter a of the $\mathrm{H}$-S model ranged in $0.0009 \sim 0.0022$ in Jiangxi and was lower than the default value (0.0023); parameter $\mathrm{b}$ of the rate determined $\mathrm{H}-\mathrm{S}$ model ranged in $0.62 \sim 0.92$ and was higher than the default value (0.5), indicating that the daily temperature range contributed significantly to the reference crop evapotranspiration in Jiangxi; parameter c of the rate determined $\mathrm{H}$-S model ranged in 7.59 28.5 and the highest and second highest value appeared in the Lushan Mountain and the Jinggangshan Mountain, indicating significant effects of altitude on this parameter (Table 2).

Parameter a of the P-T method ranged in $1.05 \sim 1.18$ and was lower than the default value (1.26), indicating that the contribution on the reference crop evapotranspira1tion by the aerodynamic term was relatively low when this method was applied in Jiangxi. Specifically, the contribution by the aerodynamic term was less than $20 \%$ of that by the radiation term without considering errors (Table 2 ).

In this study, after parameter redetermination of the I-A method, parameter $\mathrm{b}$ and c were set as 0.32 and 0.015 , respectively, and parameter a ranged in $-0.69 \sim-0.35$. Similar to the I-A method, parameter b of the Mak method ranged in $-0.37 \sim-0.08$ with parameter a being set to be 0.66. Additionally, terms in the I-A method and the Mak method are constant and could only be used for correction of overall deviations of the ultimate results. As a result, MBE of the I-A method and the Mak method was 0 (see Fig. 3d).

Parameter $a, b$, and c of the PVB method varied significantly within $-378.6 \sim 681.9,-113.7 \sim 60.2$, and $-3.43 \sim 2.63$, respectively. Hence, the esp calculated based on average temperature was highly unreliable, resulting in poor model accuracy (Table 2 ).

The B-R method has four parameters. According to the calculation equation structure, coefficients of the high temperature term, the daily temperature range term, and the extraterrestrial radiation term were above 0.1 . Despite their specific units, contributions of these three parameters to reference crop evapotranspiration were in similar scale. Also, redetermined coefficients of the extraterrestrial radiation term were basically less than half of the high temperature term, the daily temperature range term for all stations, indicating the dominant role of temperature in application of this model in Jiangxi. Contributions of the extraterrestrial radiation terms to reference crop evapotranspiration were small and the accuracy was relatively low (Table 2).

By introducing the difference term of the saturation vapor pressure and the actual vapor pressure into the B-R method, the M-B-R method has five parameters and average coefficient of the extraterrestrial radiation term was $20 \%$ higher than that of the daily temperature range term (Table 3). In other words, unlike the B-R method, the contribution of radiation on reference crop evapotranspiration was significant in the M-B-R method and its accuracy was significantly higher than that of the B-R method. 
Table 3

Calibration parameter value of different reference crop evapotranspiration methods (M-B-R, Sch, Turc, J-H and B-S)

\begin{tabular}{|c|c|c|c|c|c|c|c|c|c|c|c|c|}
\hline \multirow[t]{2}{*}{ Station name } & \multicolumn{5}{|l|}{ M-B-R } & \multirow{2}{*}{$\begin{array}{l}\text { Sch } \\
\text { a }\end{array}$} & \multirow{2}{*}{$\begin{array}{l}\text { Turc } \\
\text { a }\end{array}$} & \multicolumn{3}{|l|}{$\mathrm{J}-\mathrm{H}$} & \multicolumn{2}{|l|}{ B-S } \\
\hline & a & b & c & d & e & & & a & b & c & $\mathbf{a}$ & b \\
\hline Xiushui & 0 & 0.050 & 2.51 & -0.017 & 1.20 & 10.2 & 15.84 & 026 & 0.018 & -0.030 & -0.972 & 1.209 \\
\hline Yifeng & 037 & 0.052 & 2.78 & -0.012 & 1.27 & 10.2 & 15.65 & 0.220 & 0.084 & -0.139 & -1.079 & 1.009 \\
\hline Lianhua & 35 & 0.055 & 2.36 & -0.022 & 1.48 & 3 & 2 & 21 & 20 & 1.747 & -1.012 & .138 \\
\hline Yichun & 3 & 0.050 & 2.61 & -0.017 & 1.20 & 1 & 1 & 11 & 57 & 56 & 88 & 0.743 \\
\hline Ji'an & 0.032 & 0.055 & 2.60 & -0.012 & 1.26 & 10.6 & 17.21 & 0.006 & 3.524 & 0.241 & 141 & 0.953 \\
\hline Jinggangs & 0.035 & 0.044 & 2.48 & -0.032 & 1.09 & 10.7 & 15.68 & 0.048 & 0.509 & 0.952 & -1.271 & 0.673 \\
\hline Suichuan & 0.040 & 0.050 & 2.48 & -0.014 & 1.17 & 10.5 & 17.16 & 0.307 & 0.066 & -0.054 & -1.063 & 1.081 \\
\hline Ganzhou & 0.038 & 0.056 & 2.33 & -0.014 & 1.39 & 10.2 & 8 & 7 & 0.168 & 0 & 92 & 1.220 \\
\hline Lushan & 0.021 & 0.045 & 3.25 & -0.027 & 0.98 & 4 & 16.28 & 518 & 0.041 & -0.111 & -2.355 & 0.237 \\
\hline Wu'an & 0.050 & 0.052 & 2.52 & -0.015 & 1.36 & 10.4 & 16.49 & -0.067 & -0.306 & 0.163 & -1.059 & 1.008 \\
\hline Boyang & 0.050 & 0.051 & 2.61 & -0.019 & 1.28 & 11.1 & 17.37 & -0.160 & -0.127 & 0.130 & -1.421 & 0.670 \\
\hline Jingdezhen & 0.048 & 0.055 & 2.23 & -0.021 & 1.45 & 10.4 & 16.77 & 0.536 & 0.041 & +2 & 31 & 1.101 \\
\hline Jing'an & 0.060 & 0.053 & 2.64 & -0 . & 1.48 & 1 & 1 & 3 & 0 & 0 & 9 & 1.006 \\
\hline Nanchang & 0.042 & 0.050 & 2.62 & -0.018 & 1.20 & 10.8 & 17.21 & 0.035 & 0.663 & 1.852 & -1.424 & 0.665 \\
\hline Zhangshu & 0.052 & 0.054 & 2.23 & -0.024 & 1.43 & 10.5 & 16.51 & 0.279 & 0.068 & -0.108 & -1.167 & 0.886 \\
\hline Dexing & 0.039 & 0.045 & 2.56 & -0.020 & 1.20 & 10.0 & 16. & 0.286 & 0.071 & 0.005 & 1.036 & 1.108 \\
\hline Guixi & 42 & 0.051 & 2.3 & -0.010 & 1.12 & 1 & 1 & 40 & -0.057 & 0.1 & 091 & 1.045 \\
\hline Yushan & 0.032 & 0.046 & 2.48 & -0.017 & 1.01 & 10.7 & 16.93 & 0.086 & 0.269 & 0.657 & -1.252 & 0.814 \\
\hline Shangrao & 0.027 & 0.052 & 2.44 & -0.019 & 1.21 & 10.6 & 16.59 & 0.043 & 0.556 & 2.124 & -1.168 & 0.893 \\
\hline Yongfeng & 0.031 & 0.049 & 2.75 & -0.016 & 1.19 & 106 & 16.54 & 011 & 0.189 & 0100 & 2 & 0.987 \\
\hline Nancl & 27 & 0.042 & 3.13 & -0.014 & 0.91 & 11. & 17.48 & 0.005 & 4.529 & 0.220 & 34 & 0.709 \\
\hline Nanfeng & 0.021 & 0.050 & 2.79 & -0.013 & 1.09 & 10.8 & 17.22 & 0.729 & 0.027 & -0.036 & -1.150 & 0.931 \\
\hline Ningdu & 0.032 & 0.050 & 2.61 & -0.021 & 1.21 & 10.9 & 16.92 & 0.653 & 0.031 & -0.024 & -1.393 & 0.674 \\
\hline Guangchang & 0.025 & 0.049 & 2.73 & -0.014 & 1.12 & 10 & 16.33 & 2 & -0.080 & 0.087 & 68 & 1.051 \\
\hline Longnan & 0.030 & 0.051 & 2.82 & -0.018 & 1.34 & 10.2 & 16.05 & 0.167 & 0.126 & 0.107 & -1.179 & 0.881 \\
\hline Xunwu & 0.026 & 0.052 & 2.84 & -0.017 & 1.40 & 10.1 & 15.73 & 0.062 & 0.383 & 1.326 & -1.114 & 0.970 \\
\hline Maximum & 0.06 & 0.06 & 3.25 & -0.01 & 1.48 & 11.4 & 17.47 & 1.03 & 4.53 & 2.12 & -0.97 & 1.22 \\
\hline Minimum & 0.02 & 0.04 & 2.23 & -0.03 & 0.91 & 10.0 & 15.65 & -0.34 & -0.31 & -0.14 & -2.36 & 0.24 \\
\hline Average & 0.04 & 0.00 & 2.61 & -0.02 & 1.23 & 10.6 & 16.59 & 0.18 & 0.49 & 0.46 & -1.20 & 0.91 \\
\hline
\end{tabular}

The parameters of the Sch method ranged in $10.0 \sim 11.4$ and were lower than the default value (16). (Table 3) However, the accuracy of this method was low, suggesting that this method neglects some key factors although the effects of temperature and relative humidity have been considered. As a result, applicability of the Sch method in Jiangxi was poor. For the Turc method, parameter b ranged in 15.65 $\sim 17.47$ if parameter a was set to be 0.018 . Considering the fact that redetermination led to limited improvement on the model accuracy, it was concluded that the Turc method could be directly applied in Jiangxi. Parameter a, b, and c of the J-H method ranged in $-0.34 \sim 1.03$, $-0.31 \sim 4.53$, and $-0.14 \sim 2.12$, respectively, and the parameter values varied significantly. This demonstrated that the $\mathrm{J}-\mathrm{H}$ method was not reliable, thus not applicable in Jiangxi (Table 3 ). 
With parameter a of the B-S method set to be 0.69 , parameter $b$ and c ranged in $-2.36 \sim-0.97$ and $0.24 \sim 1.22$, respectively, and the contribution of the wind speed on the aerodynamic term was adjusted by these two parameters. Moreover, as the aerodynamic term in this method was negative, parameter b should be negative to bring positive contribution to the aerodynamic term (Table 3).

\subsection{Redetermined monthly values by different evapotranspiration calculation methods}

Figure 4 shows deviations of monthly values by different evapotranspiration methods after redetermination. As observed, the monthly variation was less than $3 \mathrm{~mm}$ for the 48PM method, indicating good applicability. For the H-S method, deviations in April to August ranged in $4 \sim 10 \mathrm{~mm}$ and errors would be exacerbated in calculations of water demands of crops as crop coefficients were usually larger than 1 in this period. The absolute deviation of the P-T method was relatively high in October to December. However, this period was not the major water consumption period for crops, the P-T method was applicable in Jiangxi. The monthly absolute deviations of the I-A method were highly consistent ( $<4 \mathrm{~mm}$ even in April to August), indicating the good applicability of the I-A method in Jiangxi. The absolute deviation of the Mak method was relatively high in July and August (under-estimation was $8.9 \mathrm{~mm}$ for July and $5.9 \mathrm{~mm}$ for August), demonstrating that the Mak method was inferior to the P-T method in terms of applicability in Jiangxi. The monthly absolute deviations of the PVB method were highly consistent ( $<3 \mathrm{~mm}$ in May to September). The B-R method exhibited over-estimations of $6 \mathrm{~mm}$ in May to July and severe under-estimations in July and August. Compared with the B-R method, the M-B-R method exhibited significant reductions of monthly absolute deviations, although under-estimations of $5 \mathrm{~mm}$ were observed in July and August. The monthly absolute deviations of the Sch method were above $5 \mathrm{~mm}$ and maximized in July to November. Redetermination by month may enhance the applicability of this model. The monthly absolute deviations of the Turc method were highly consistent $(<5 \mathrm{~mm})$ and maximized deviations appeared in January and July. The J-H method exhibited under-estimations of $10 \mathrm{~mm}$ in October to April and over-estimations of $5 \mathrm{~mm}$ in July and August, demonstrating that the $\mathrm{J}-\mathrm{H}$ method was not applicable in Jiangxi. The monthly absolute deviations of the B-S method were small, demonstrating good applicability of this method in Jiangxi.

\subsection{Annual values by improved evapotranspiration methods}

In the background of global climate change, model applicability may vary significant with time. Figure 5 shows the model applicability in Jiangxi with interannual deviation, which facilitated the study. The annual $E T_{0}$ calculated by various methods exhibited significant variation around 2003. Herein, the 48PM method exhibited over-estimations of 20 30 mm p.a. in 1961 to 2002 and 10 mm p.a. below after 2003. The H-S method exhibited under-estimation before 1990s, over-estimation of 10 40 mm p.a. in 1995 to 2002 , and underestimation of $0 \sim 25$ mm p.a. after 2003. The P-T method exhibited negligible deviations before 2005 and under-estimation of 40 mm p.a. after 2005 .

The Mak method, the PVB method, the B-R method, the M-B-R method, and the Sch method shared similar trends in long term: the results shifted gradually from under-estimation to over-estimation before 2003, and the trends changed significantly after 2004. More specifically, annual under-estimation of the PVB method and the Mak method ranged in $20 \sim 50 \mathrm{~mm}$ and the absolute deviation of the B-R method ranged in -30 $30 \mathrm{~mm}$. The M-B-R method exhibits significant over-estimation (70 $110 \mathrm{~mm})$ after 2003. The Sch method exhibits significant over-estimation (above $50 \mathrm{~mm}$ ) after 1995. Limited by severe deviations in certain periods, neither of the five methods mentioned above could precisely reflect trends of reference crop evapotranspiration. The Turc method exhibited small annual deviations before 2003 , but the significant under-estimation $(25 \sim 50 \mathrm{~mm}$ ) were observed after 2005 . The J-H method exhibited annual underestimations above $100 \mathrm{~mm}$ and it was further exacerbated after 2005. Therefore, the J-H method was not applicable in Jiangxi. The B-S method exhibited annual under-estimation in $0 \sim 10 \mathrm{~mm}$, indicating that the overall deviation of the B-S method was minimum among that of all 12 methods. The long term ET 0 curve of the B-S method was highly consistent with that of the P-M method.

\subsection{Spatial distribution of errors in different models}

Figure 6 shows spatial distribution of $\mathrm{N}_{\mathrm{RMSE}}$ of the PM method and other $\mathrm{ET}_{0}$ calculation methods in Jiangxi. $\mathrm{N}_{\mathrm{RMSE}}$ was maximized in the middle and north part of Jiangxi in all models, while minimized $\mathrm{N}_{\mathrm{RMSE}}$ appeared in different areas. For instance, minimized $\mathrm{N}_{\mathrm{RMSE}}$ was located in the east and west mountains in the H-S method, the P-T method, the I-A method, the PVB method, and the Turc method, while minimized $\mathrm{N}_{\mathrm{RMSE}}$ was located in southern Jiangxi in the 48PM method, the Mak method, the B-R method, the M-B-R method, the Sch method, and the B-S method. For the J-H method, $\mathrm{N}_{\mathrm{RMSE}}$ was maximized in northern and southern Jiangxi (north > south) and minimized in the middle part.

Overall, the B-S method and the 48P-M method shows optimized accuracy (maximized $\mathrm{N}_{\mathrm{RMSE}}<5 \%$ ), followed by the P-T method, the I-A method, the Mak method, the PVB method, and the Turc method $\left(\mathrm{N}_{\mathrm{RMSE}}=0.1 \sim 0.2\right)$. In all these methods, overall surface radiation or net 
radiation has been considered and led to significant improvement for the accuracy. Among temperature-based methods, the $\mathrm{J}-\mathrm{H}$ method was slightly better than the $\mathrm{H}-\mathrm{S}$ method, while $\mathrm{N}_{\mathrm{RMSE}}$ of data by other methods ranged in $0.3 \sim 0.4$, indicating that applicability of these methods was limited.

\section{Discussion}

The applicability of simplified ETO models exhibits obvious regional differences due to various controlling factors in ET0 for different climates (Feng, cui, Zhao, 2016; Salam, Islam, Pham, 2020). Our study area, Jiangxi province, has a subtropical monsoon climate, characterized by a high precipitation amount and a high spatiotemporal variability of precipi338tation and solar radiation. Previous studies have demonstrated soil radiation dominates ETO in Jiangxi (Fan, Yue, Wu, 2018). Compared with other radiation-based models, the Turc model performed the best. The B-R, M-B-R and J-H models have large errors because the default parameter values are not suitable for the local region.

The 48PM method has been widely applied globally (Li, Cui, Yu, \& Wei, 2016; Matsui, \& Osawa, 2015; Xu, Peng, Ding, \& Wen, 2010), but it is limited by severe errors before parameter redetermination. For instance, $R_{M S E}$ of data by the 48PM method was between $1.18 \mathrm{~mm} / \mathrm{d}$ and $2.13 \mathrm{~mm} / \mathrm{d}$ (Li, Cui, Yu, \& Wei, 2016) in Sichuan, above 1.1mm/d in Kunshan, Jiangsu (Xu, Peng, Ding, \& Wen, 2010), and about $0.5 \mathrm{~mm} / \mathrm{d}$ in the middle and lower reaches of Yangtse River (Jia, Cui, Wei, Gong, \& Hu, 2016). Nevertheless, applicability of the B-S method has not been studied in China. In this study, $\mathrm{R}_{\mathrm{MSE}}$ of data by the 48PM method before parameter redetermination ranged in $1.25 \sim 3 \mathrm{~mm} / \mathrm{d}$ in Jiangxi and the error was mainly attributed to over-estimation of the aerodynamic term. After parameter redetermination, $\mathrm{R}_{\mathrm{MSE}}$ of data by the 48PM method ranged in $0.06 \sim 0.34 \mathrm{~mm} / \mathrm{d}$, the annual over-estimation of data by the 48PM method was below $30 \mathrm{~mm}$ and decreased since 2003. On the other hand, $R_{\text {MSE }}$ of data by the B-S method ranged in $0.08 \sim 0.27 \mathrm{~mm}$ and the annual over-estimation of data by the $B-$ $\mathrm{S}$ method was below $20 \mathrm{~mm}$. With comparable accuracy to the P-M method, the 48PM method and the B-S method involves no information about wind speed in the radiation term, thus they are more suitable for investigations of contributions by the radiation term and the aerodynamic term to reference crop evapotranspiration and the mechanism behind.

Tabari (2010) evaluated applicability of the Makkink method, the Turc method, the H-S method, and the P-T method in Iran, and proposed that the Turc method exhibited optimized applicability. Qin et. al. (2016) reported that the Turc method showed good applicability in Qinhuaihe District only in September to November and no significant advantages in the upper reach of the Yellow River (Du et al., 2013; Li, 2012). In this study, average $R_{\text {MSE }}$ and $N_{\text {RMSE }}$ of data by the Turc method redetermination were $0.39 \mathrm{~mm} / \mathrm{d}$ and 0.157 m, respectively, while redetermination brought no significant enhancement. In summary, the Turc method could be directly applied in Jiangxi.

The P-T method is a calculation method for reference crop evapotranspiration commonly applied in humid regions. In this method, the aerodynamic term was neglected and the contribution by this term was covered by multiplying the radiation term by a coefficient larger than 1 (the default value is 1.26). Basically, $\mathrm{ET}_{0}$ would be over-estimated in humid regions and under-estimated in arid regions (EstãVez, GavilãiN, \& Berengena, 2010; Szilagyi, 2014). In this study, Parameter $a$ of the P-T method ranged in $1.05 \sim 1.18$ and the method presents excellent performance in April to August. Therefore, the P-T method is an alternative method in absence of data about wind speed and relative humidity. Shared similar structure with the P-T method, the Mak method showed advantages in accuracy over the P-T method in Northwestern China (Wang, Song, \& Han, 2009; Wu et al., 2016). However, in this study the Mak method was inferior to the P-T method in terms of accuracy and applicability, and it exhibited under-estimation by $6 \mathrm{~mm}$ and $9 \mathrm{~mm}$ in July and August, respectively.

It should be pointed out that the results by the P-M method were used as the reference data in this study. However, these data were not perfectly aligned with practical evapotranspiration data, and the reliable evaluations of applicability of different calculation methods for crop evapotranspiration in regional scale need further efforts. Bormann evaluated performances of 18 simplified evapotranspiration models in the background of climate changes (Bormann, 2011). The results demonstrated that $\mathrm{ET}_{0}$ is sensitive to meteorological factors to different degrees. The annual $\mathrm{ET}_{0}$ calculated by different methods (except the 48PM method and the B-S method) exhibited significant variations around 2003. This may be attributed to significant changes in certain meteorological factors over recent years. The 48PM method and the B-S method shared identical climatological data with the P-M method, and the changes could be reflected by annual ET 0 . Also, it indicated that fixed empirical parameters in empirical methods could not reflect effects by key meteorological factors in long time simulations in the background of climate changes. The intensive studies on the causes and key meteorological factors of $\mathrm{ET}_{0}$ in Jiangxi province would facilitate the selection of appropriate empirical models, thus improving their applicability and reducing the risks.

\section{Conclusions}


The $\mathrm{N}_{\mathrm{RMSE}}$ was maximized in Northern Jiangxi for all methods, while minimized $\mathrm{N}_{\mathrm{RMSE}}$ by different models appeared in different regions. Performances of irradiation-based methods were better than those of temperature-based ones.

The 48PM method and the B-S method showed good applicability after parameter redetermination: their $\mathrm{R}_{\mathrm{MSE}}$ and $\mathrm{N}_{\mathrm{RMSE}}$ ranged in $0.06 \sim$ $0.34 \mathrm{~mm} / \mathrm{d}$ and $0.08 \sim 0.27 \mathrm{~mm}$, respectively, and their annual over-estimations were below $30 \mathrm{~mm}$. $\mathrm{R}_{\mathrm{MSE}}$ and $\mathrm{N}_{\mathrm{RMSE}}$ of the Turc method were $0.389 \mathrm{~mm} / \mathrm{d}$ and $0.157 \mathrm{~mm}$, respectively before parameter redetermination and the values didn't vary significantly after parameter redetermination. The Turc method can be used in Jiangxi (except Nanchang). In the absence of relative humidity and wind speed, the P-T method was an appropriate simplified method for Jiangxi. In this case, a was between the default value $1.05 \sim 1.18, \mathrm{R}_{\mathrm{MSE}}$ was within 0.21 $\sim 0.66 \mathrm{~mm} / \mathrm{d}$, and $\mathrm{N}_{\text {RMSE }}$ was within $0.08 \sim 0.30 \mathrm{~m}$. Owing to severe monthly and annual deviations, the H-S method, the B-R method, and the M-B-R method showed poor accuracy.

In the background of climate changes, applications of empirical methods are challenged. The intensive studies of reasons on the causes and key meteorological factors of $\mathrm{ET}_{0}$ in Jiangxi would facilitate selection of appropriate empirical models, thus improving their applicability and reducing the risks.

\section{Declarations}

\section{Conflict of Interest}

The authors declare that they have no known competing financial interests or personal relationships that could have appeared to influence the work reported in this paper.

\section{Acknowledgements}

The authors extend their gratitude to the National Meteorological Information Center of China Meteorological Administration for offering the meteorological data.

\section{Funding information}

This study was jointly supported by National Natural Science Foundation of China (No.51669015) هthe Educational Commission of Jiangxi Province, China (GJJ190977, GJJ190946)and Water Science andTechnology Planning Project of Jiangxi Province, China(KT201717).

\section{Autor's Contribution}

Xianghui Lu devised the project, the main conceptual ideas and proof outline. Haina Zhang and Yixiu Han designed the computational framework and analysed the data. Hua Bai and Erhui Li performed the calculations. Xianghui Lu andHaina Zhang verified the numerical results.. All authors discussed the results and contributed to the final manuscript.

\section{References}

1. Akhavan, S., Kanani, E., \& Dehghanisanij, H. (2018). Assessment of different reference evapotranspiration models to estimate the actual evapotranspiration of corn (Zea mays L.) in a semiarid region (case study, Karaj, Iran). Theoretical and Applied Climatology.

2. Albrecht, F. (1950). Die Methoden zur Bestimmung der Verdunstung der natürlichen Erdoberfläche. Archiv Für Meteorologie Geophysik Und Bioklimatologie Serie B, 2(1-2): 1-38.

3. Allen, R. G., Pereira, L. S., Raes, D., \& Smith, M. (1998). Crop evapotranspiration-guidelines for computing crop water requirements, Vol. 300: 6541 .

4. Bormann, H. (2011). Sensitivity analysis of 18 different potential evapotranspiration models to observed climatic change at German climate stations. Climatic Change, 104(3-4): 729-753.

5. Caprio, J. M. (1974). The Solar Thermal Unit Concept in Problems Related to Plant Development and Potential Evapotranspiration, Phenology and seasonality modeling: 353-364. Berlin: Springer.

6. Djaman, K., Balde, A. B., Sow, A., Muller, B., Irmak, S., N’Diaye, M. K., Manneh, B., Moukoumbi, Y. D., Futakuchi, K., \& Saito, K. (2015). Evaluation of sixteen reference evapotranspiration methods under sahelian conditions in the Senegal River Valley. Journal of Hydrology Regional Studies, 3: 139-159.

7. Du, J. Q., Xiong, S. S., Liu, C. C., Guo, Y., Shu, J. M., \& Zhang, L. B. (2013). Comparison of models for estimating reference crop evapotranspiration in the headwater catchment of the Yellow River basin,China. Arid Land Geography.

Page $12 / 18$ 
8. Estã Vez, J., GavilãiN, P., \& Berengena, J. N. (2010). Sensitivity analysis of a Penman-Monteith type equation to estimate reference evapotranspiration in southern Spain. Hydrological Processes, 23(23): 3342-3353.

9. Fan, J. , Yue, W. , Wu, L. , Zhang, F. , Cai, H. , \& Wang, X. , et al. (2018). Evaluation of svm, elm and four tree-based ensemble models for predicting daily reference evapotranspiration using limited meteorological data in different climates of china. Agricultural and Forest Meteorology, 263, 225-241.

10. Feng, Y. , Cui, N. , Zhao, L. , Hu, X. , \& D Gong. (2016). Comparison of elm, gann, wnn and empirical models for estimating reference evapotranspiration in humid region of southwest china. Journal of Hydrology, 376-383.

11. Hargreaves, G. H., \& Allen, R. G. (2003). History and evaluation of Hargreaves evapotranspiration equation. Journal of Irrigation Drainage Engineering, 129(1): 53-63.

12. Irmak, S., Irmak, A., Allen, R. G., \& Jones, J. W. Solar and Net Radiation-Based Equations to Estimate Reference Evapotranspiration in Humid Climates. Journal of Irrigation and Drainage Engineering.

13. Jia, Y., Cui, N. B., Wei, X. P., Gong, D. Z., \& Hu, X. T. (2016). Applicability evaluation of different algorithms for reference crop evapotranspiration in Yangtze River Basin based on inverse distance weighted method. Transactions of the Chinese Society of Agricultural Engineering.

14. Li, C., Cui, N. B., Yu, F., \& Wei, X. P. (2016). Adaptation evaluation for reference evapotranspiration methods in different regions of Sichuan. Transactions of the Chinese Society of Agricultural Engineering, 32(4): 127-134.

15. Li, Z. (2012). Applicability of simple estimating method for reference crop evapotranspiration in Loess Plateau. Transactions of the Chinese Society of Agricultural Engineering, 28(6): 106-111.

16. Liu, X. Y., Li, Y. Z., \& Wang, Q. S. (2006). Evaluation on several temperature-based methods for estimating reference crop evapotranspiration. Transactions of the CSAE, 22(6): 12-18.

17. Makkink, G. F. (1957). Testing the Penman formula by means of lysimeters. International Journal of Water Engineering(11): $277-288$.

18. Matsui, H., \& Osawa, K. (2015). Calibration effects of the net longwave radiation equation in Penman-type methods at Tateno, Japan. Hydrological Research Letters, 9(4): 113-117.

19. Muniandy, J. M., Yusop, Z., \& Askari, M. (2016). Evaluation of reference evapotranspiration models and determination of crop coefficient for Momordica charantia and Capsicum annuum. Agricultural Water Management, 169: 77-89.

20. Paredes, P., Fontes, J. C., Azevedo, E. B., \& Pereira, L. S. (2018). Daily reference crop evapotranspiration in the humid environments of Azores islands using reduced data sets: accuracy of FAO-PM temperature and Hargreaves-Samani methods. Theoretical and Applied Climatology.

21. Qin, M. S., Hao, L., Shi, T. T., Sun, L., \& Sun, G. (2016). Comparison and Modification of Five Crop Reference Evapotranspiration Models for Qinhuai River Basin. Chinese Journal of Agrometeorology.

22. Salam, R. , Islam, A. , Pham, Q. B. , Dehghani, M. , \& Linh, N. . (2020). The optimal alternative for quantifying reference evapotranspiration in climatic sub-regions of bangladesh. Scientific Reports, 10(1), 20171.

23. Szilagyi, J. (2014). Temperature corrections in the Priestley-Taylor equation of evaporation. Journal of Hydrology, 519: $455-464$.

24. Tabari, H. (2010). Evaluation of Reference Crop Evapotranspiration Equations in Various Climates. Water Resources Management, 24(10): 2311-2337.

25. Wang, S. P., Song, L. C., \& Han, Y. X. (2009). Estimation of the Potential Evapotranspiration in Paramos. Arid Zone Research, 26(26): 126-129.

26. Wang, W. G., Peng, S. Z., Yang, T., Shao, Q. X., \& Xing, W. Q. (2011). Spatial and Temporal Characteristics of Reference Evapotranspiration Trends in the Haihe River Basin, China. Journal of Hydrologic Engineering, 16(3): $239-252$.

27. Wu, L. F., Bai, H., Zhang, F. C., Lu, X. H., Wang, J. W., \& Ying, L. H. ( 2016). Applicability of FAO Penman-Monteith and alternative methods for estimating reference evapotranspiration in northwest China. Transactions of the Chinese Society for Agricultural Machinery, 47(12): 139-151.

28. Xu, J. Z., Peng, S. Z., Ding, J. L., \& Wen, Z. (2010). Evaluation of methods for estimating daily reference crop evapotranspiration based on lysimeter grass experiments. Journal of Hydraulic Engineering, 41(12): 1497-1505.

29. Yuan, X. H., Yang, X. J., Chen, C., \& Wu, J. Y. (2014). Applicability assessment of reference evapotranspiration models in Beijing based on lysimeter measurement. Transactions of the Chinese Society of Agricultural Engineering, 30(13): 104-110.

30. Zhang, Q., Duan, A. W., Gao, Y., Shen, X. J., \& Cai, H. J. (2015). Comparative analysis of reference evapotranspiration estimation methods using temperature data. Transactions of The Chinese Society of Agricultural Machinery, 46(2): 104-109. 


\section{Figures}

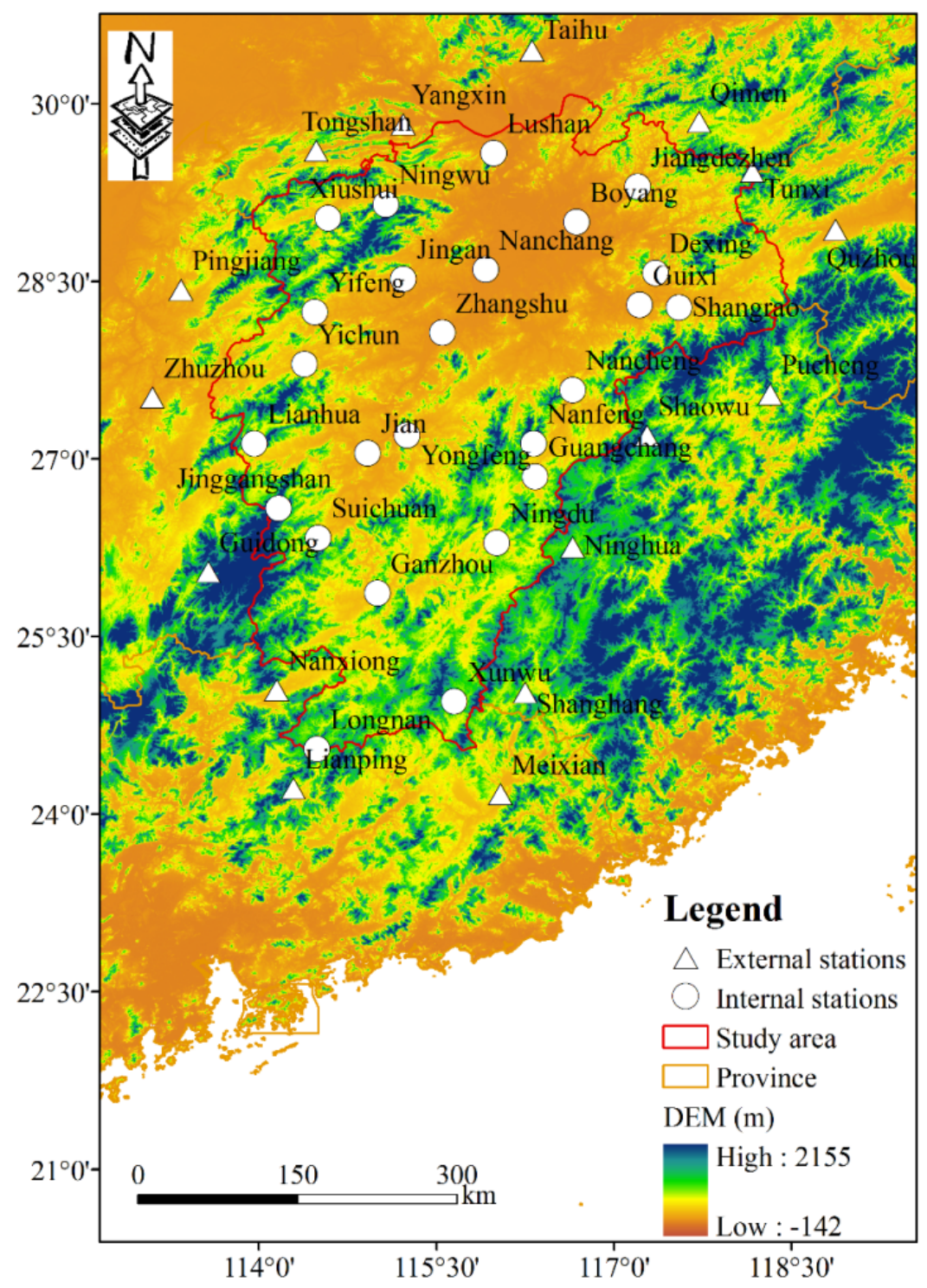

\section{Figure 1}

Distribution of 43 meteorological observation sites around Jiangxi province. 

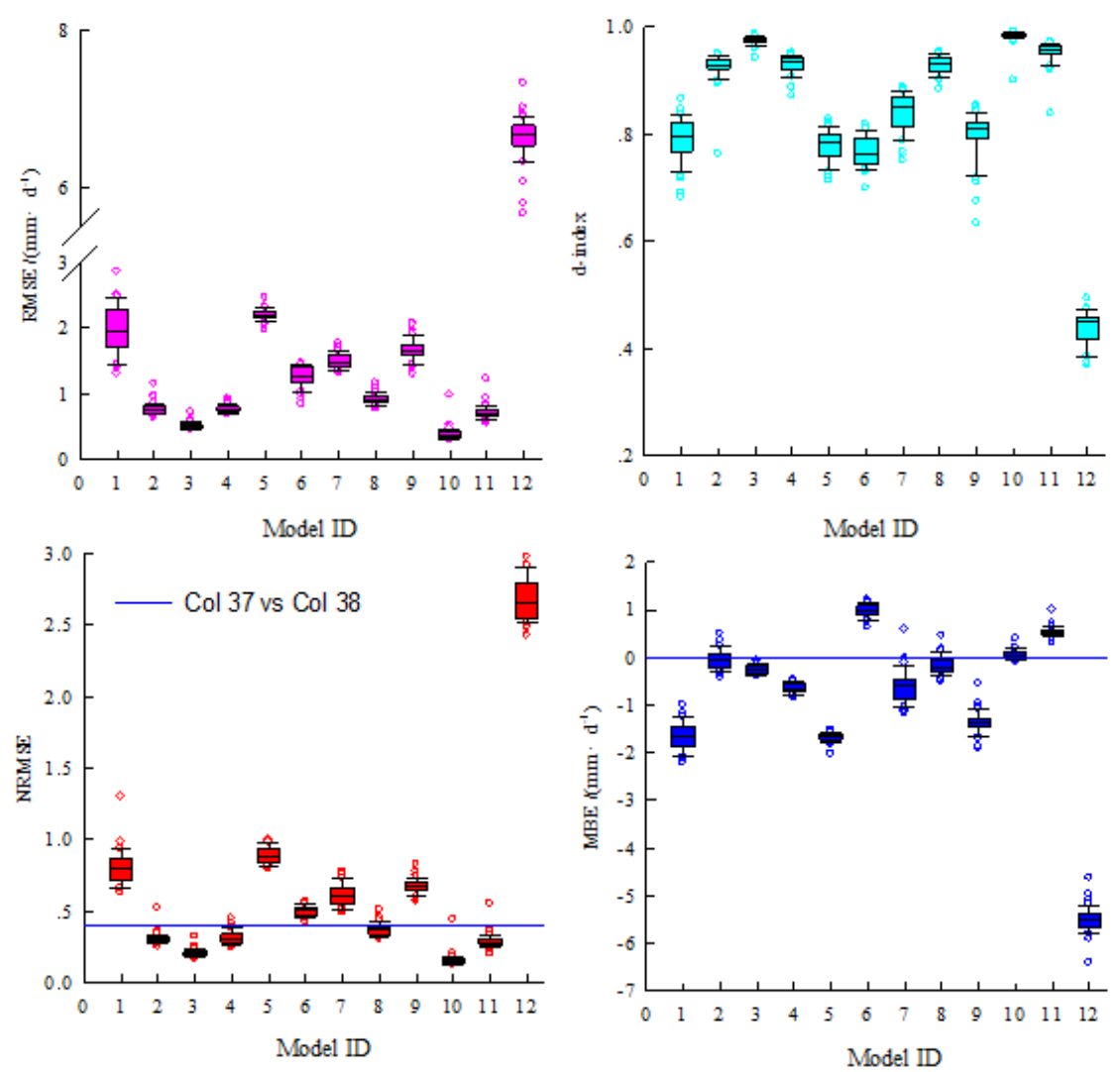

\section{Figure 2}

Statistic results of difference reference crop evapotranspiration calculation methods under default parameters.
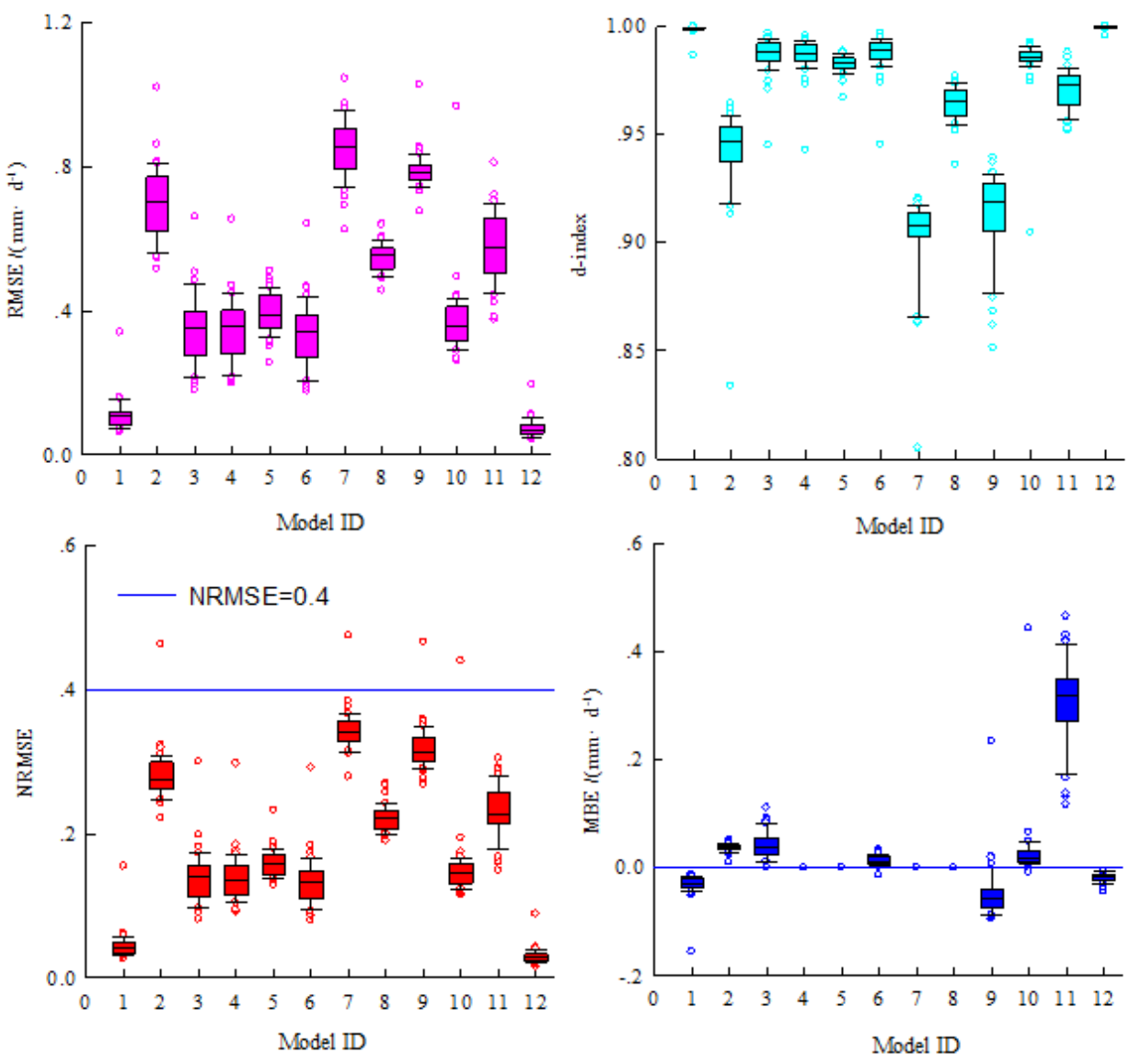

Page $15 / 18$ 


\section{Figure 3}

Statistic results of difference reference crop evapotranspiration calculation methods under calibrated parameters.
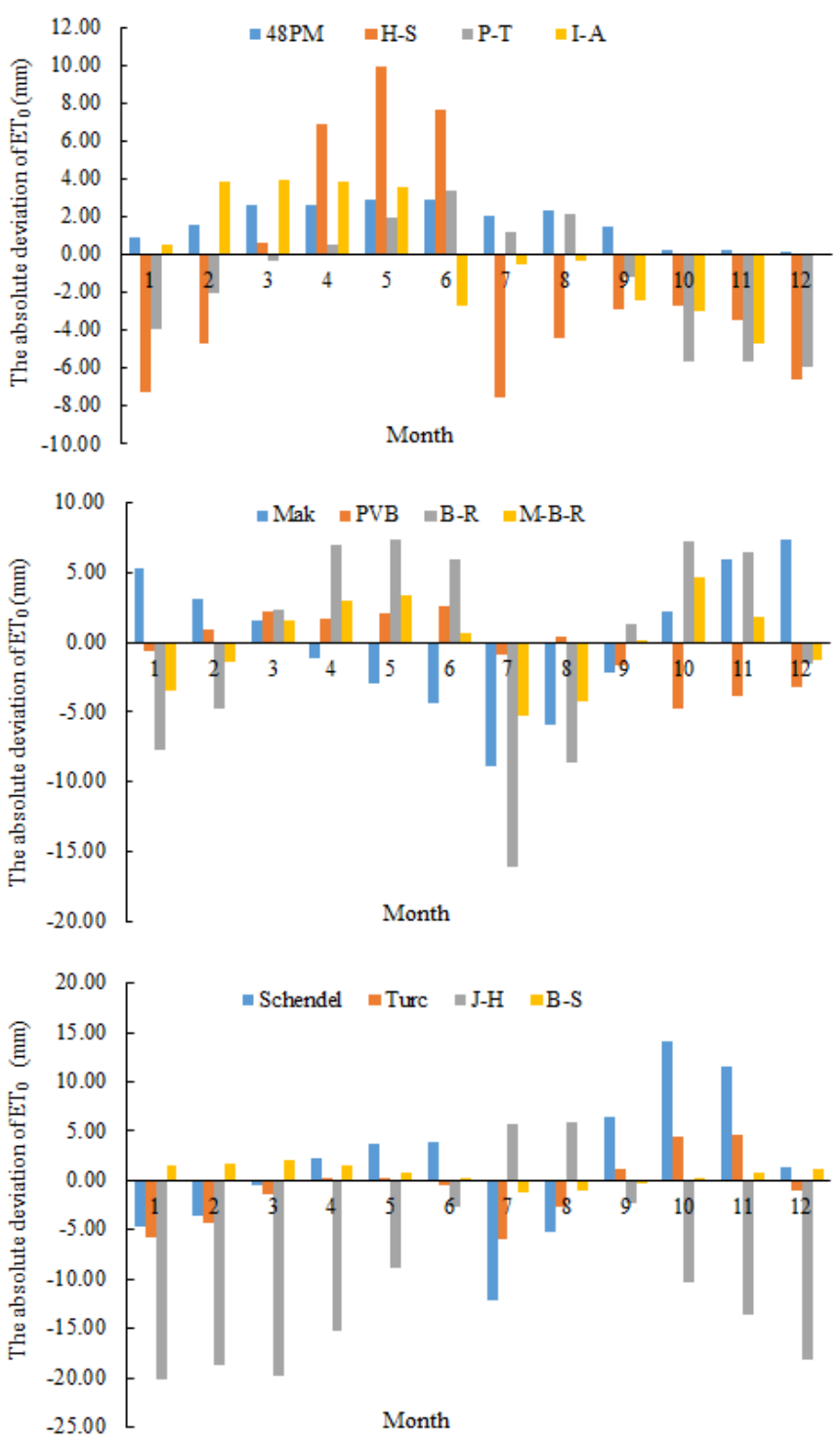

\section{Figure 4}

Absolute error of different calculation methods for evapotranspiration of reference crop (ET0) in each month. 

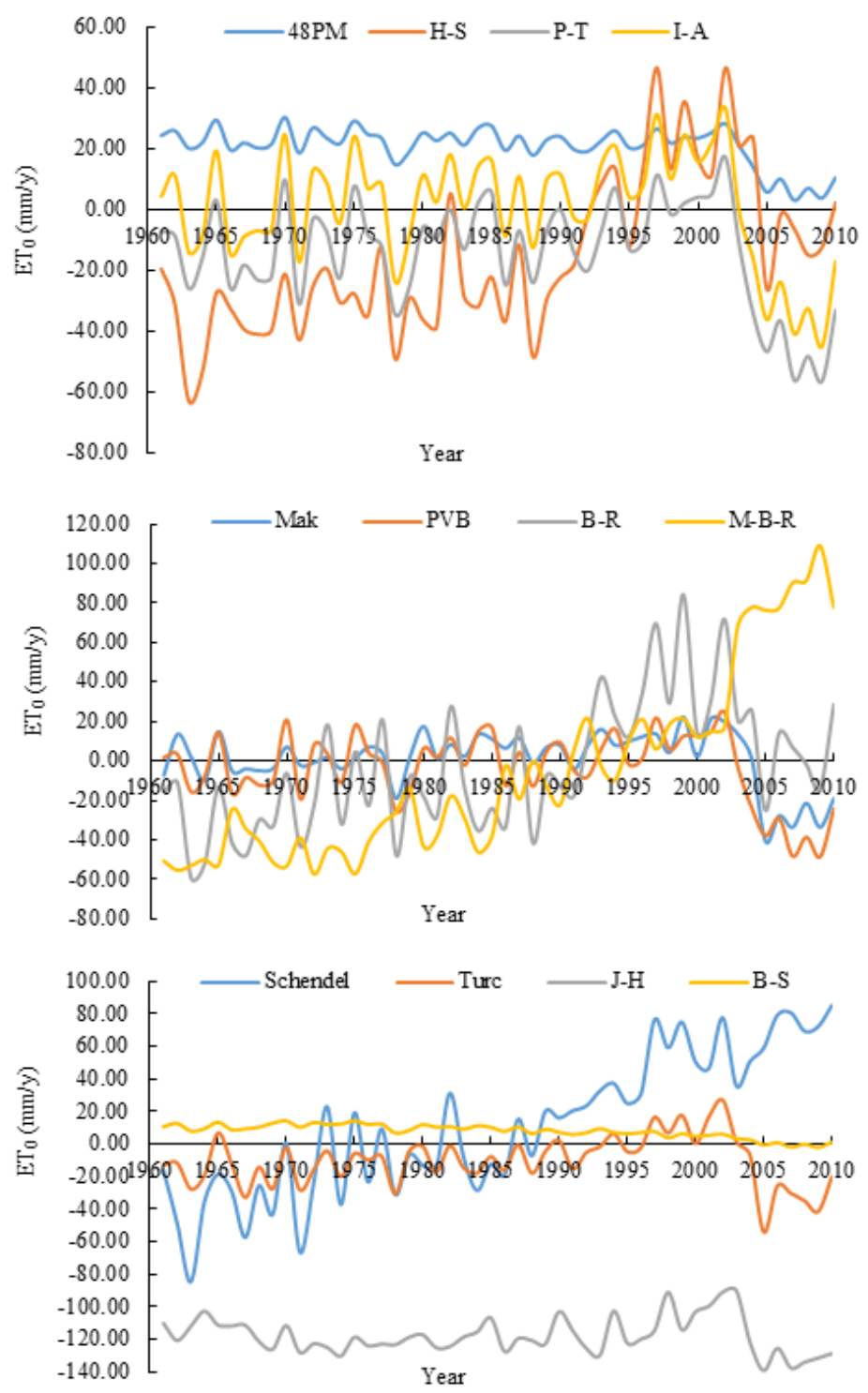

\section{Figure 5}

Absolute error of different calculation methods for reference crop evapotranspiration of (ET0) in 1961-2010. 

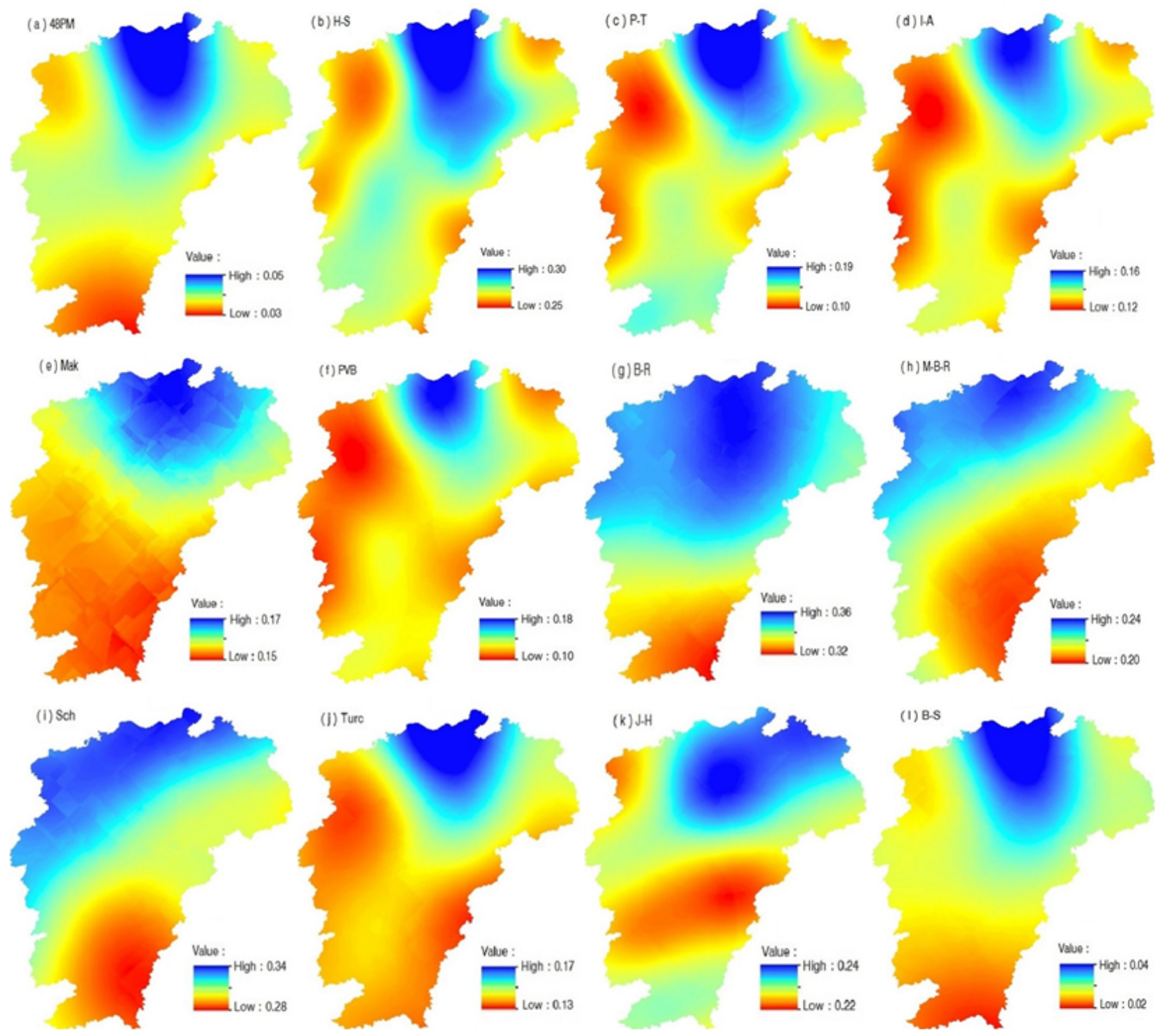

\section{Figure 6}

Spatial distribution of NMRSE of reference crop evapotranspiration and difference methods in Jiangxi province. (a) 48PM (b) H-S (c) P-T (d) I-A (e) Mak (f) PVB (g)B-R (h) M-B-R (i) Sch (j) Turc (k) J-H (I) B-S 